\title{
Características Estruturais, Petrográficas e Geoquímicas de Enxame de Diques Máficos Intrusivo em Rochas Metassedimentares do Greenstone Belt de Crixás, Goiás
}

\author{
Structural, Petrographic and Geochemical Characteristics of Mafic Dikes Intrusive in \\ Metasedimentary Rocks of the Crixás Greenstone Belt, Goiás
}

\author{
Hardy Jost ${ }^{1}$ (hmc_jost@opendf.com.br) e Jayme Estevão Scandolara ${ }^{2}$ (scandolara@df.cprm.gov.br) \\ 'Departamento de Geoquímica e Recursos Minerais - Instituto de Geociências - UnB \\ Campus Universitário Darcy Ribeiro - Asa Norte, CEP 70919-990, Brasília, DF, BR \\ ${ }^{2}$ Serviço Geológico do Brasil - CPRM, Brasília, DF, BR
}

Recebido em 07 de junho de 2010; aceito em 17 de agosto de 2010

\section{RESUMO}

Diques e raros stocks máficos são comuns nos terrenos arqueanos de Goiás, onde ocorrem em enxames de $2.3-2.5 \mathrm{Ga}$ nos complexos granito-gnáissicos $(2.8$ e $2.7 \mathrm{Ga})$ e nas seções estratigráficas inferiores de metakomatiitos e metabasaltos, mas eram desconhecidos nas unidades metassedimentares superiores dos greenstone belts. $\mathrm{O}$ detalhamento de seções de sondagem de área dos depósitos auríferos do greenstone belt de Crixás revelou que a intrusão destes diques ocorreu após os principais eventos de deformação e metamorfismo paleoproterozoicos da seção metassedimentar e sobre os quais dados de literatura indicam que zircão magmático dos mesmos possui a idade de $2170 \pm 17$ Ma. Dados petrográficos e geoquímicos registram tratar-se de diabásios com características composicionais de basaltos epicratônicos de alto-Ti semelhantes aos da Bacia do Paraná. A idade das intrusões se correlaciona com o curto intervalo de tempo $(2,20$ a 2,17 Ga) do Rhyaciano, durante o qual ocorreram sucessivos e localizados episódios de plumas mantélicas no Globo Terrestre.

Palavras-chave: Geoquímica; Diques máficos; Paleoproterozoico; Greenstone belt; Crixás; Goiás.

\section{ABSTRACT}

Mafic dikes and stocks are a common feature in the Archean terrain of Goiás, Central Brazil, where they occur as swarms of $2.3-2.5 \mathrm{Ga}$ within the granite-gneiss complexes $(2.8$ e $2.7 \mathrm{Ga})$, as well as intrusions related to the komatiite and basalt flows of the greenstone belts lower stratigraphic units, but were unknown within the upper metasedimentary units. Detailed study of core sections from several drill-sites in the area of the Crixás greenstone belt gold deposits showed that dike intrusion occurred after the main Paleoproterozoic deformation and metamorphism of the metasedimentary units, and literature data indicate that the magmatic zircons from the dikes yielded an age of 2,170 \pm 17 Ma. Petrographic and geochemical data show that they have the composition of epicratonic high-Ti diabases, which are similar to the large continental flood basalts of the Paraná Basin. The age of the intrusions may be correlated with the short time-interval of the Rhyacian (2.20 to $2.17 \mathrm{Ga}$ ), during which successive localized episodes of mantle plume volcanism occurred on the Earth.

Keywords: Geochemistry; Mafic dikes; Paleoproterozoic; Greenstone belt; Crixás; Goiás. 


\section{INTRODUÇÃO}

Diques e raros stocks máficos são comuns nos terrenos arqueanos de Goiás, onde ocorrem como enxames nos complexos granito-gnáissicos de idade entre 2,8 e 2,7 Ga (Queiroz et al., 2008) e nas seções estratigráficas inferiores de metakomatiitos e metabasaltos dos greenstone belts. As características estruturais, petrográficas, geoquímicas e geocronológicas das intrusões nos complexos granito-gnáisicos foram descritas por Kuyumjian (1998), Girardi et al. (1992), Tomazolli (1997), Corrêa da Costa (2003), Corrêa da Costa, Girardi e Teixeira (2002) e Corrêa da Costa e Girardi (2005) e dados geocronológicos destes diques registram idade entre 2,3 e 2,5 Ga (Tomazzoli e Nilson, 1994; Tomazolli, 1997; Corrêa da Costa, Girardi, Teixeira, 2006). Por outro lado, diques associados aos metakomatiitos e metabasaltos dos greenstone belts não foram ainda detalhados e as ocorrências nas unidades metassedimentares superiores eram desconhecidas, mas passaram a ser reconhecidas com frequência crescente nos últimos anos em testemunhos de sondagem das rochas hospedeiras da mineralização aurífera do greenstone belt de Crixás (Figura 1). A datação de zircão magmático por LA-ICP-MS destes diques gerou a idade $2170 \pm 17 \mathrm{Ma}$ (Jost et al., 2010) e por U-Pb SHRIMP e LA-ICP-MS de zircão detrítico de metagrauvacas e filito carbonoso que alojam os diques indica que a idade das rochas-fonte dos detritos varia de 2,2 a 3,4 Ga (Tassinari et al., 2006; Jost et al., 2008). Portanto, a intrusão dos diques ocorreu em cerca de 30 a $50 \mathrm{Ma}$ após a sedimentação, deformação e metamorfismo das rochas metassedimentares e, por conseguinte, representa evento magmático distinto dos demais. Este artigo visa descrever a posição espacial, relações e efeitos de contato com as rochas encaixantes, estruturas primárias e secundárias, características petrográficas e geoquímicas e significado tectônico dos diques que ocorrem no pacote metassedimentar de Crixás, a partir de resultados de levantamento de dados e amostragem de sondagens da área da propriedade da Mineração Serra Grande S.A.

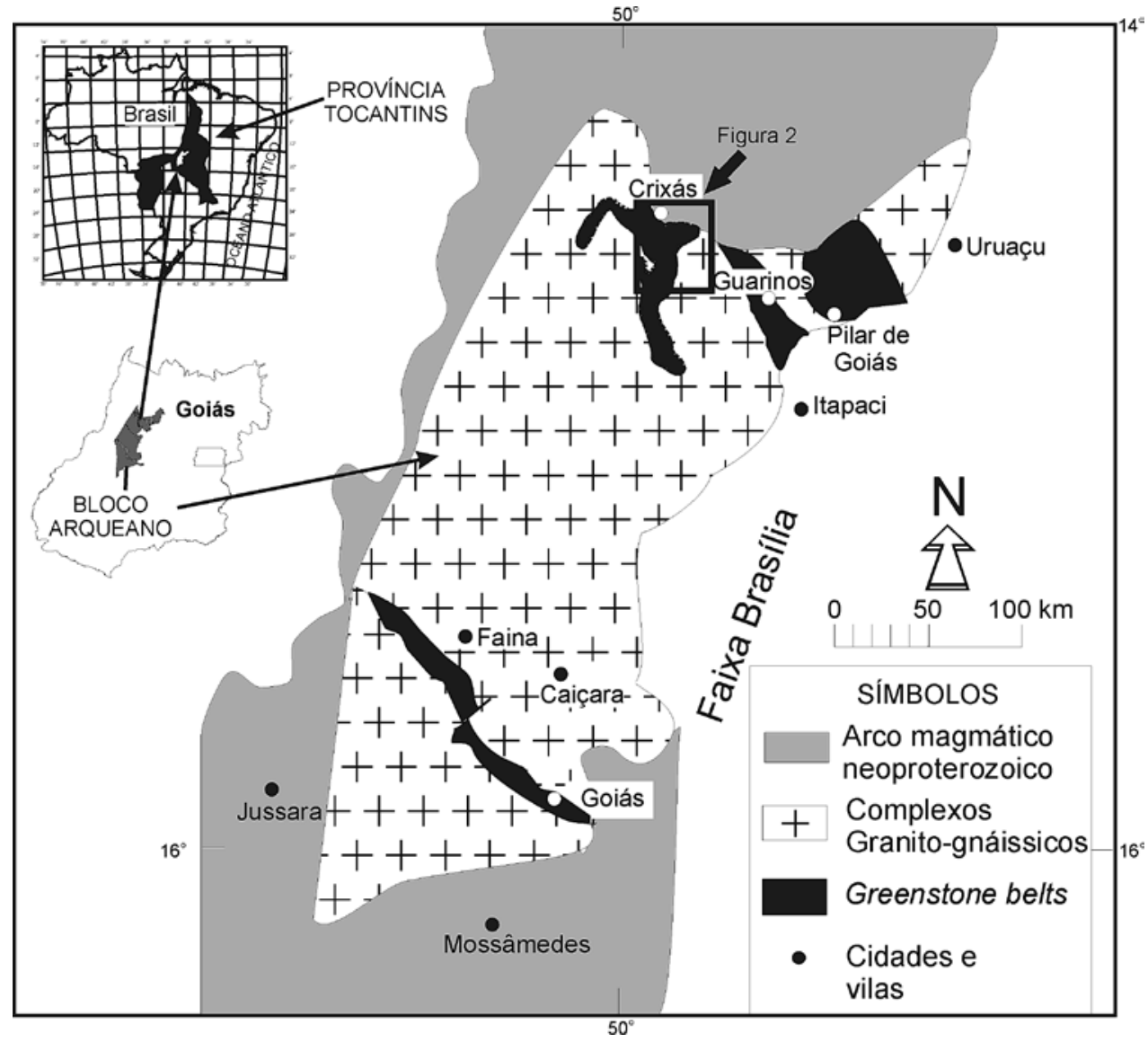

Figura 1. Localização e principais domínios do terreno arqueano de Goiás. 


\section{GEOLOGIA REGIONAL E LOCAL}

O greenstone belt de Crixás (Figura 1) limita-se no oeste e leste com complexos granito-gnáissicos compostos por protólitos batolíticos de tonalito, granodiorito e granito juvenis $\left(\varepsilon_{\mathrm{Nd}}=0,01\right.$ a 2,41$)$ de idade entre $2,85 \mathrm{Ga}$ e 2,80 Ga (Queiroz et al., 2008) e ao norte está sotoposto a uma das escamas de empurrão de rochas metassedimentares neoproterozoicas do Arco Magmático de Mara Rosa. Em planta, o greenstone belt tem contorno irregular festonado devido ao soerguimento de corpos individuais de unidades de gnaisses adjacentes e se subdivide em uma porção meridional e outra setentrional, separadas por zona de cisalhamento $\mathrm{N} 60^{\circ} \mathrm{W}$. A meridional é composta apenas de metakomatiitos e a setentrional consiste da base para o topo, de metakomatiitos e metabasaltos seguidos de rochas metassedimentares. Sabóia (1979) reúne os metakomatiitos, metabasaltos e rochas metasse- dimentares nas formações Córrego Alagadinho, Rio Vermelho e Ribeirão das Antas, respectivamente, reunidas por Jost e Oliveira (1991) no Grupo Crixás (Figura 2).

A espessura preservada dos metakomatiitos da Formação Córrego Alagadinho é estimada em cerca de 900 m no setor meridional e de $500 \mathrm{~m}$ no setentrional, seus protólitos tiveram composição peridotítica e piroxenítica e, por metamorfismo, foram transformados em xistos com proporções variadas de talco, clorita, serpentina, carbonato, actinolita, magnetita e/ou cromita. Feições vulcânicas primárias, tais como texturas spinifex e cumulática, brechas de fluxo e disjunções poliédricas são locais. A espessura preservada dos metabasaltos da Formação Rio Vermelho é de cerca de $300 \mathrm{~m}$ e seus protólitos foram derrames, sills e diques composicionalmente primitivos, transformados em anfibólio xistos com ferro-actinolita a ferro-tschermakita, proporções subordinadas de albita ou oligoclásio e menores de clorita, clinozoisita, quartzo, pirita

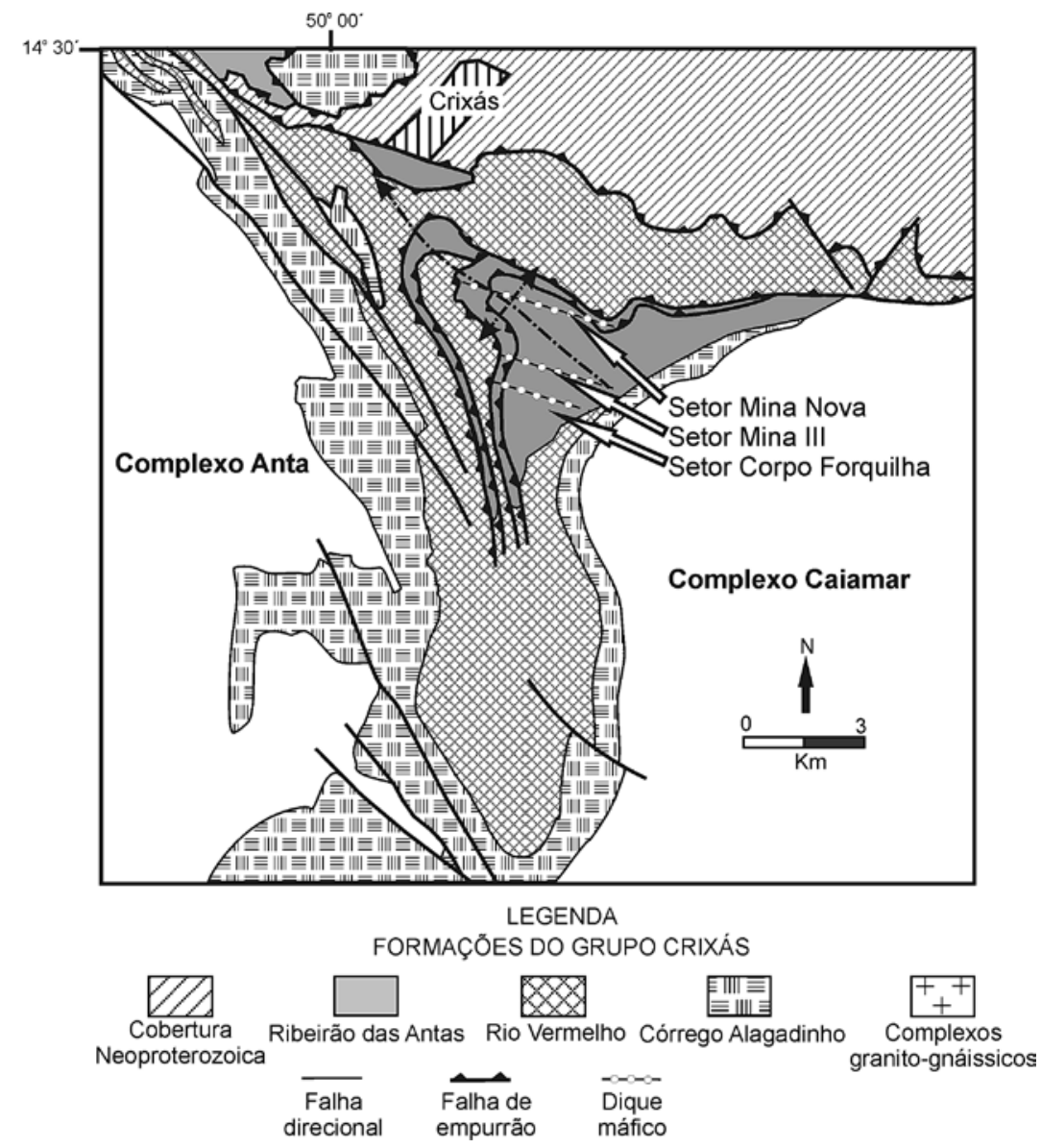

Figura 2. Mapa geológico simplificado da porção norte do greenstone belt de Crixás que mostra a distribuição das unidades estratigráficas e a localização aproximada dos setores de ocorrência dos diques estudados. Modificado de Massucato (2004). 
ou magnetita. Feições vulcânicas primárias compreendem pillows, varíolas e vesículas. As rochas metassedimentares da Formação Ribeirão das Antas têm espessura mínima de $400 \mathrm{~m}$ e compreendem da base para o topo, xistos carbonosos com lentes de dolomito e metagrauvacas. As paragêneses metamórficas das seções de rochas metavulcânicas indicam condições das fácies xisto verde médio a anfibolito inferior e as da seção sedimentar da fácies xisto verde inferior a médio.

Dados estruturais da porção setentrional do greenstone belt obtidos por Magalhães (1991), Queiroz (1995) e Massucato (2004) sugerem que esta contém o registro de pelo menos quatro eventos de deformação. O mais antigo resultou em dobras com formação da foliação metamórfica $(\mathrm{Sn})$ paralela ao acamamento original (So), indicativo de transposição generalizada de So e que Sn é superfície axial de dobras regionais isoclinais. Segue-se proeminente deformação resultante de descolamento e desenvolvimento de falhas de empurrão epidérmicas regionais, de baixo ângulo e vergência nordeste, com a concomitante formação de dobras assimétricas e, na área mineralizada com ouro, de um duplex. Este evento resultou na sobreposição de metakomatiitos aos metabasaltos e destes ao pacote metassedimentar e consequente inversão estratigráfica. $\mathrm{O}$ evento seguinte, de compressão de norte para sul, favoreceu o cavalgamento de rochas do arco magmático neoproterozoico de Mara Rosa sobre a porção norte do greenstone belt, no qual se desenvolveram dobras recumbentes a semi-recumbentes de vergência para sudoeste. O traçado de $\mathrm{Sn} / / \mathrm{So}$, do contato entre metakomatiitos, metabasaltos e a seção metassedimentar e das falhas de empurrão mostram que este evento foi responsável pelo arqueamento do greenstone belt e geração de ampla antiforme regional (Antiforme Rio Vermelho - Magalhães, 1991) de superfície axial N60 $\mathrm{W}$, $30^{\circ} \mathrm{SW}$. O último evento resultou de compressão de leste para oeste, responsável pela ondulação do greenstone belt e desenvolvimento de clivagem de crenulação.

As idades de 2,2 Ga de cristais de zircão mais jovens do pacote metassedimentar e de 2,17 Ga dos diques máficos indicam que o segundo evento de deformação é do Paleoproterozoico (Rhyaciano), ao passo que dados geocronológicos das paragêneses de alteração hidrotermal metamorfizadas de corpos auríferos obtidos por Fortes, Pimentel e Teixeira (1993) e Fortes et al. (1997, 2003) indicam que os dois últimos eventos de deformação são do Neoproterozoico.

\section{RELAÇÕES ENTRE DIQUES MÁFICOS E ESTRUTUURA DAS ROCHAS ENCAIXANTES}

O reconhecimento dos diques máficos ocorreu em testemunhos de sondagem, mas não em superfície devido ao manto de intemperismo relativamente espesso constituído de latossolo vermelho que se confunde com a alteração de metagrauvacas. A estimativa da sua orientação e a observação das relações dos diques com a estrutura das rochas metassedimentares encaixantes foi realizada a partir da análise das 37 sondagens distribuídas em oito seções transversais, seis orientadas segundo N-S, três das quais no setor da Mina Nova (vide Figura 2), distantes em média $150 \mathrm{~m}$, quatro no da Mina III e uma E-W no do Corpo Forquilha, e exemplificado pela Figura 3. A distância mínima entre sondagens foi de $40 \mathrm{~m}$ e a máxima de $150 \mathrm{~m}$. Os perfis foram construídos a partir de arquivos digitalizados das sondagens e redesenhados com rebatimento à vertical das sondagens com desvio. Os testemunhos das sondagens foram revisitados nos intervalos com registro de dique nos perfis digitalizados e abrangendo $30 \mathrm{~m}$ acima e abaixo das ocorrências, seguido da correlação entre as sondagens para definir as relações dos diques com a sucessão e o estilo estrutural das rochas metassedimentares encaixantes e dos intervalos auríferos. Os diques têm de $1 \mathrm{~m}$ a $20 \mathrm{~m}$ de largura e a partir da correlação entre as sondagens dos perfis N-S estimou-se que sua atitude seja $\mathrm{N} 70^{\circ} \mathrm{W}, 10^{\circ}-35^{\circ} \mathrm{N}$.

As relações entre os diques e a estrutura das rochas encaixantes estão bem expostas nos testemunhos de sondagem e lâminas delgadas de amostras do contato. Nas seções N-S o pacote metassedimentar dobrado e metamofisado têm, em geral, baixo mergulho para sul ou é sub-horizontal e os diques mergulham para norte, em relação de recorte. Por outro lado, os diques possuem foliação não penetrativa seguida, por vezes, de crenulação, em contraste com as rochas encaixantes, as quais contêm pelo menos duas fases de deformação marcadas pela foliação metamórfica dobrada. Isto indica que os diques intrudiram as rochas metassedimentares após seu dobramento e metamorfismo paleoproterozoicos e precedem as deformações neoproterozoicas do greenstone belt.

\section{EFEITOS DE CONTATO SOBRE AS ROCHAS ENCAIXANTES IMEDIATAS}

Para verificar os efeitos de contato termal dos diques sobre as rochas metassedimentares encaixantes e estimar a profundidade de intrusão selecionaram-se duas amostras de filito carbonoso e duas de metagrauvaca das imediações do contato e duas de filito carbonoso e uma de dolomito de xenólito. Os efeitos termais são menos proeminentes em filito carbonoso (Figura 4A) do que em metagrauvaca e dolomito. Os efeitos sobre filito carbonoso são incipientes a ausentes, como denota a aparente preservação de quartzo, biotita e mica branca originais, o que pode ser atribuído ao caráter refratário deste litótipo. Apesar de o grau de cristalinidade de material carbonoso ser dependente de temperatura, detectável por difratometria de raios-X, não 


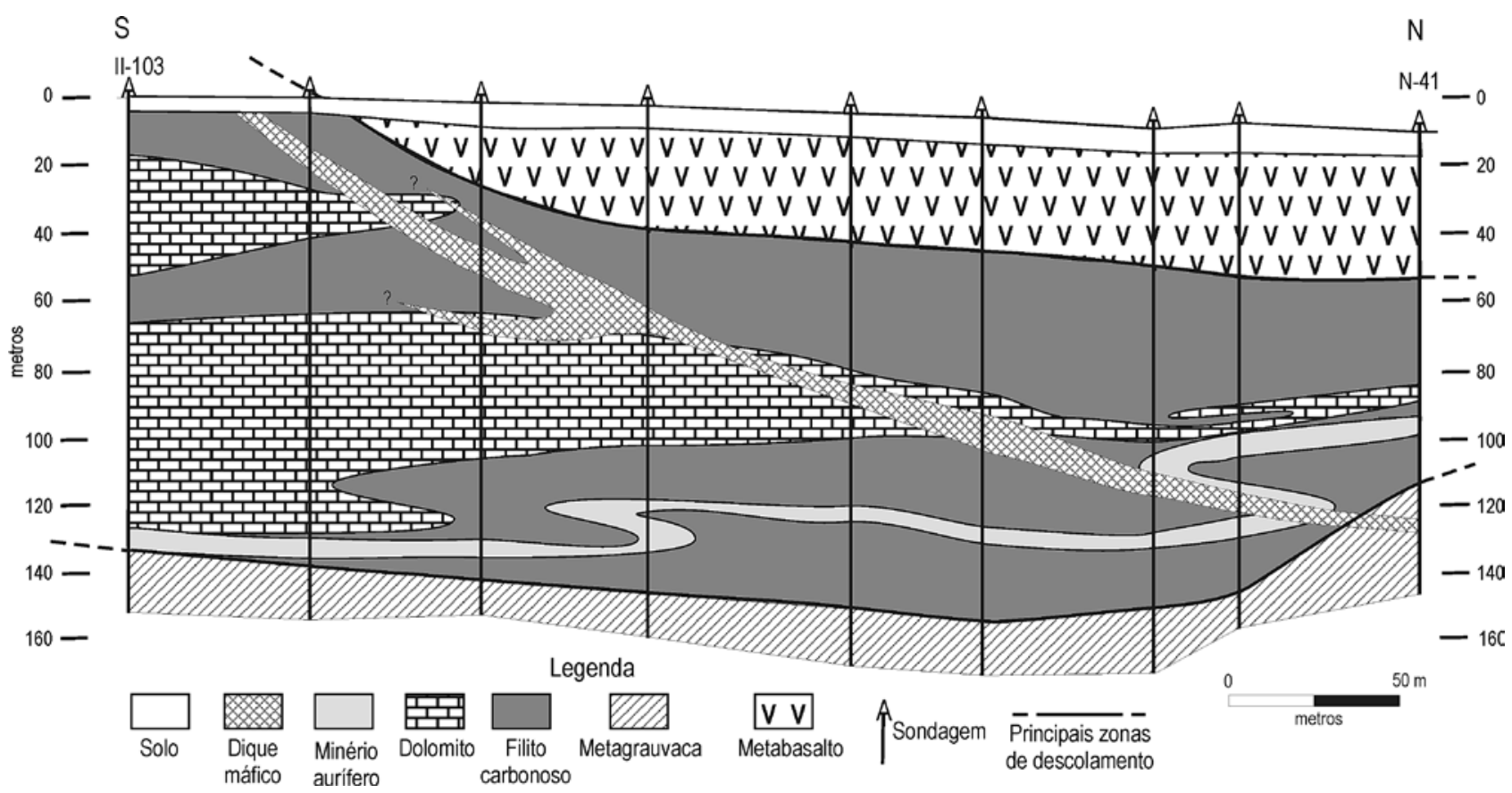

Figura 3. Seção N-S de sondagens segundo a coordenada UTM 611000 E na área da Mina Nova que exemplifica as relações de diques máficos com a estrutura das rochas metassedimentares encaixantes do greenstone belt de Crixás.

foram realizadas análises para reconhecer o eventual efeito termal dos diques sobre o material carbonoso destes filitos.

Os efeitos termais sobre metagrauvaca são representados por duas modificações texturais em quartzo e biotita, se comparadas com amostras distais aos diques. O quartzo ocorre em duas variedades texturais, sendo uma compatível com grãos detríticos irregulares a subarredondados inferiores a $0,1 \mathrm{~mm}$, por vezes recristalizados por metamorfismo, e outra consiste em grãos ameboides (Figuras 4B e 4C) superiores a $0,1 \mathrm{~mm}$, com diminutas inclusões de clorita da matriz, interpretados como de recristalização termal. A biotita também ocorre em duas variedades texturais, uma resultante de metamorfismo e compatível com o mineral em metagrauvaca distal aos diques e outra de provável recristalização termal que ocorre como fenoblastos de até $1 \mathrm{~mm}$, sem orientação preferencial, com contornos ameboides (Figura 4C) e crescidos sobre a matriz metamórfica. A Figura 4D, de metagrauvaca distal, foi incluída para efeitos de comparação com a submetida a efeitos termais da Figura 4C.

Efeitos termais sobre o xenólito de dolomito são proeminentes devido a sua maior reatividade. $\mathrm{O}$ xenólito, com $10 \mathrm{~cm}$ de comprimento, continha níveis composicionais distintos (Figura 4E) dados por borda de agregado de cristais poligonais de quartzo com trilhas de acículas orientadas de tremolita e eventual carbonato. A partir das bordas as ban- das se alternam entre níveis ricos em cristais euédricos de carbonato poligonal com aciculas de tremolita e níveis de tremolitito com ou sem carbonato e quartzo. O núcleo do xenólito é estreito nível de dolomito branco, fino, com raros cristais de tremolita. A alternância sugere diferentes intensidades das reações termais, talvez em decorrência de variações composicionais do dolomito original frente à temperatura e à pressão de $\mathrm{CO}_{2}$ e $\mathrm{H}_{2} \mathrm{O}$. Em vista disto, interpretamos os efeitos termais sobre dolomito como os esperados na formação de escarnitos de baixa temperatura.

A preservação de filossilicatos de filito carbonoso, a recristalização de quartzo e biotita em metagrauvaca e a ausência, dentre outros, de granada, escapolita, diopsídio e vesuvianita, mas de tremolita em equilíbrio com quartzo e carbonato em dolomito, sugerem que os efeitos termais dos diques sobre as rochas metassedimentares ocorreram sob $400^{\circ} \mathrm{C}$ a $500^{\circ} \mathrm{C}$ e pressão máxima de $2 \mathrm{~Kb}$, sugestivo de intrusão ocorreu em nível crustal de baixa profundidade.

\section{ESTRUTURAS PRIMÁRIAS E SECUNDÁRIAS}

As estruturas primárias dos diques compreendem xenólitos e vesículas. Xenólitos são frequentes, apesar de não registrados em todas as seções analisadas, são milimétricos a centimétricos e de filito carbonoso, por vezes de dolomito e metagrauvaca. Vesículas (Figura 5A) são raras, 

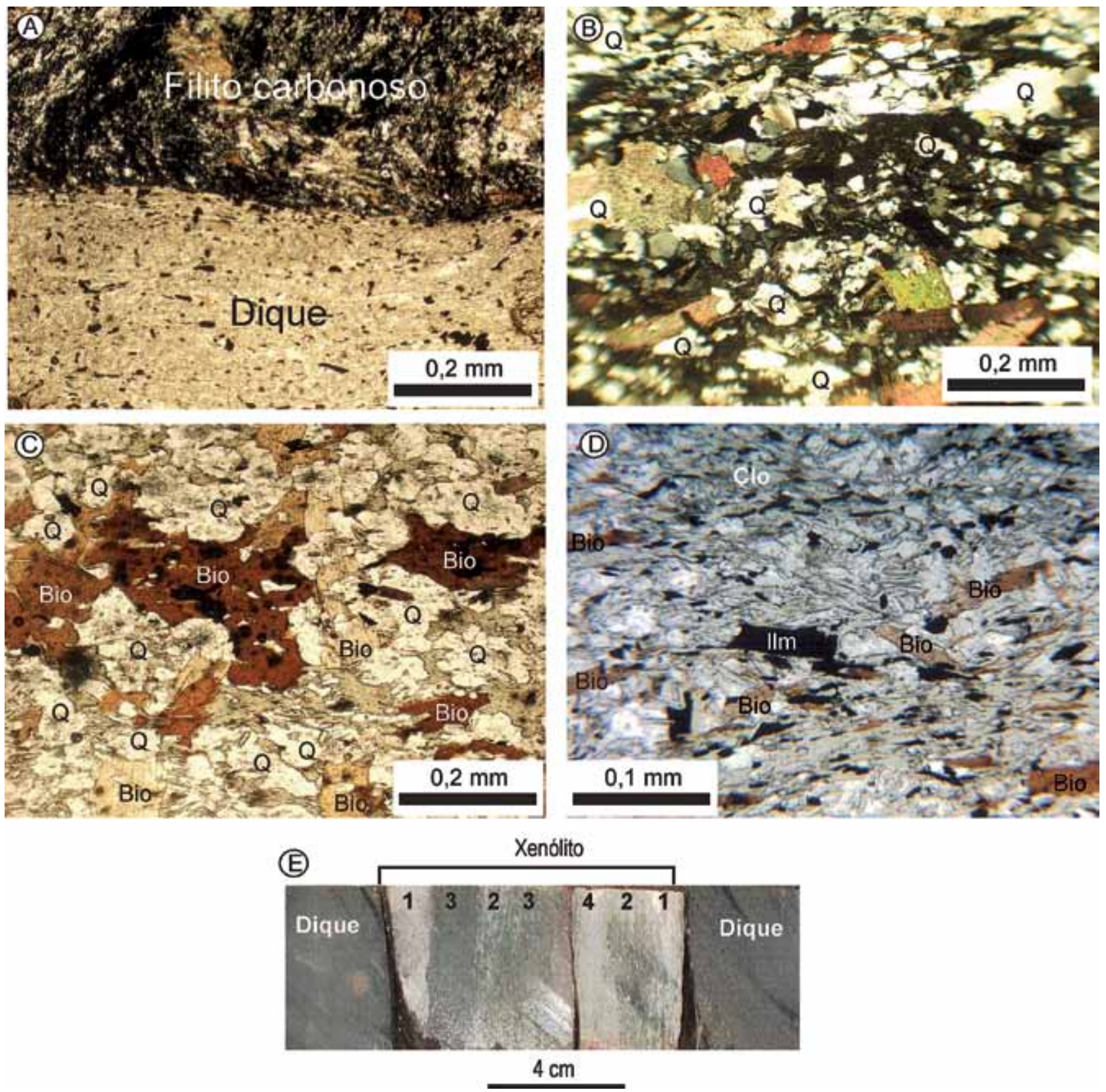

Figura 4. Efeitos termais de diques máficos sobre as rochas metassedimentares. A. Fotomicrografia do contato entre dique e filito carbonoso sem recristalização termal. LN. B. Fotomicrografia de metagrauvaca com grãos maiores de quartzo ameboide (Q) com diminutas inclusões de clorita da matriz que contrastam com grãos detríticos menores não recristalizados. LP. C. Fotomicrografia de metagrauvaca com fenoblastos de biotita ameboide (Bio) com inclusões de quartzo e opaco, e de quartzo ameboide $(Q)$ resultantes de recristalização termal. LN. D. Fotomicrografia de metagrauvaca distal aos diques, rica em clorita (Clo) com biotita (Bio), quartzo (grãos brancos) metamórficos eminerais opacos (llm = ilmenita), para comparação com a da foto 4C. LN. E. Fotografia de testemunho de sondagem de dique com xenólito de dolomito recristalizado. Associações: 1 = quartzo + tremolita; 2 = carbonato + tremolita; 3 = tremolitito; 4 = dolomito. 
de diâmetro milimétrico até $1 \mathrm{a} 2 \mathrm{~cm}$, circulares, lenticulares ou achatadas e, independente da dimensão, possuem borda de quartzo enfumaçado e núcleo de calcita.

As estruturas secundárias compreendem foliação e clivagem de crenulação. Diques estreitos são em geral foliados ao longo de todo intervalo dos testemunhos ao passo que nos espessos a foliação se restringe às bordas e é discreta a ausente no núcleo. A clivagem de crenulação é feição local e, em lâmina delgada, é acompanhada de kink-bands e microlithons foliados.

A presença de vesículas sugere cristalização em baixa profundidade e os xenólitos indicam que a intrusão ocor- reu em fraturas abertas. Por outro lado, a natureza pouco penetrativa da foliação seguida de crenulação sugerem que os diques foram submetidos a apenas dois eventos de deformação, em contraste com os quatro eventos registrados nas rochas encaixantes.

\section{PETROGRAFIA}

Estudos petrográficos de 21 amostras de núcleos de dique de vários intervalos de sondagem permitiram reconhecer a ocorrência de 11 amostras uralitizadas e $10 \mathrm{com}$ alteração avançada dada por proporções variadas de bioti-
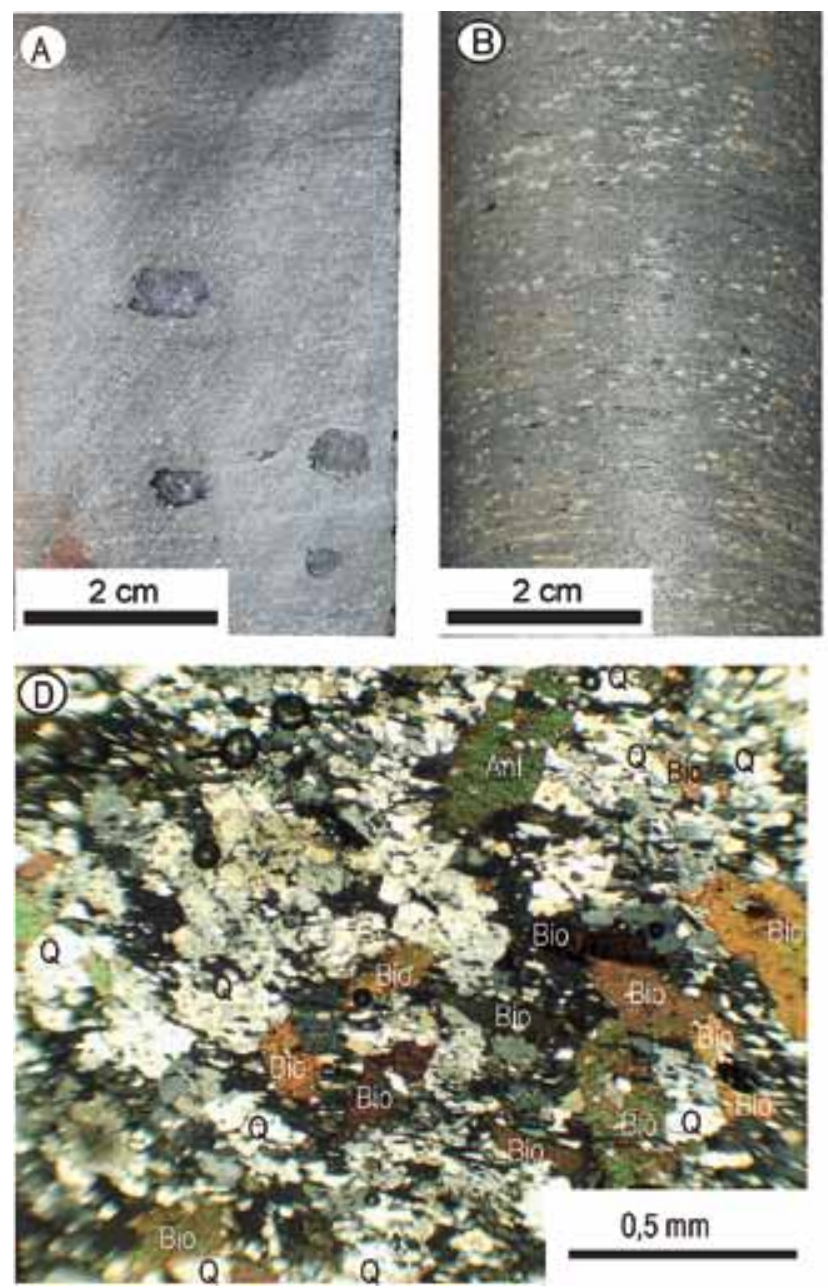
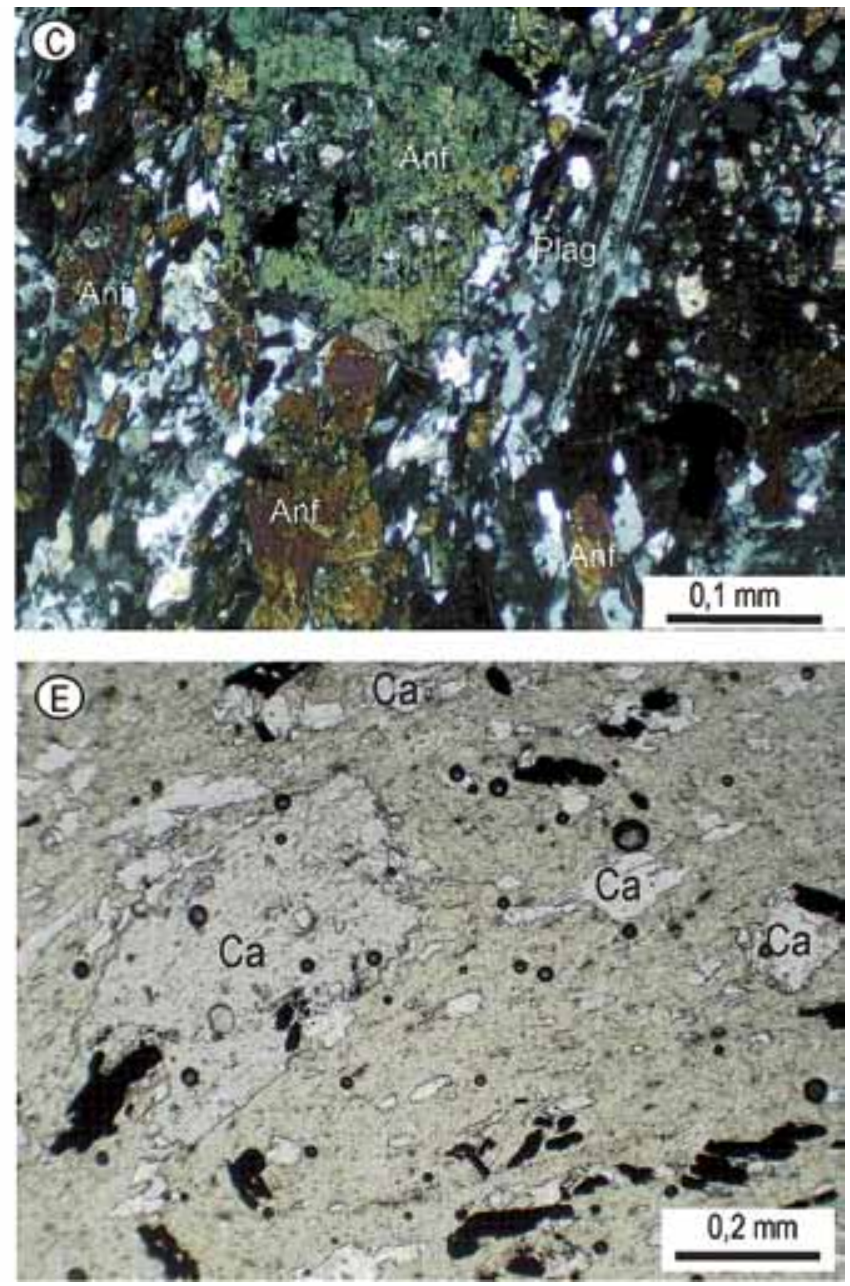

Figura 5. A. Testemunho de sondagem de dique máfico sem foliação e com vesículas. B. Testemunho de sondagem de dique discretamente foliado. Pontuações brancas são de plagioclásio. C. Fotomicrografia de dique sem alteração que mostra as duas variedades de anfibólio (Anf) e plagioclásio (Plag), uma com fenoclastos de até 2 mm, onde o anfibólio possui inclusões poiquilíticas de quartzo e outra participante da matriz de cominuição. Cristais brancos intersticiais da matriz são de quartzo. LP. D. Fotomicrografia de dique com alteração representada por biotita (Bio), quartzo (Q), com restos de anfibólio (Anf). LP. E. Fotomicrografia de dique com alteração extrema que resultou na formação de $\mathrm{Mg}$-clorita e fenoblastos de carbonato (Ca). Cristais opacos são de ilmenita. LN. 
ta, clorita, quartzo, mica branca, leucoxênio e carbonato. Amostras de núcleos uralitizados são interpretadas como representativas de intervalos ígneos mais preservados e ocorrem apenas em diques de largura superior a $5 \mathrm{~m}$ e, nestes, a alteração se restringe a menos de $1 \mathrm{~m}$ a partir das margens. Lâminas delgadas de 10 amostras do contato dos diques mostram que as associações de minerais de alteração independe da espessura dos diques, o que sugere que as transformações resultaram da interação das intrusões com fluidos provenientes das rochas metassedimentares encaixantes.

\section{Amostras uralitizadas}

Em amostra de mão, exemplares uralitizados são verde escuro, médios a finos e ora maciços e ora foliados de modo incipiente a moderado (Figura 5B). Sob microscópio, as amostras menos deformadas têm textura granular primária e protomilonítica subordinada (Figura 5C) dada por cerca de $10 \%$ de matriz cominuída composta de subgrãos finos a muito finos. Amostras mais deformadas são foliadas e sua textura é lepidoblástica a granoblástica subordinada e recuperada, com augens milimétricos de agregados granulares reliquiares contornados pela foliação e sombras de pressão discretamente assimétricas. Em ambas as variedades os constituintes maiores compreendem anfibólio $(60 \%$ - 70\%), plagioclásio, proporções subordinadas de quartzo e traços de ilmenita, pirita, clinozoisita, zircão, apatita e rara clorita.

$\mathrm{O}$ anfibólio das amostras menos deformadas ocorre em duas variedades texturais. A mais abundante consiste de fenoclastos de até $5 \mathrm{~mm}$ envoltos por matriz protomilonítica. A presença de inclusões poiquilíticas de quartzo (Figura 5C) sugere que esta variedade é produto de uralitização do piroxênio original. A mais rara participa da matriz em subgrãos milimétricos irregulares, orientados e intercrescidos com ilmenita, pirita e eventual quartzo e plagioclásio, ou como trilhas de clastos milimétricos, irregulares e intercrescidos com subgrãos de quartzo e plagioclásio. Ambas as variedades possuem propriedades ópticas idênticas caracterizadas por pleocroísmo amarelo claro a verde-claro e verde-azulado e ângulo de extinção em torno de $25^{\circ}$, indicativo de hornblenda, de provável composição pargasítica. Isto sugere que, nestas amostras, a cominuição e formação de subgrãos de anfibólio não foi acompanhada de recuperação para a espécie de mais baixa temperatura durante a deformação. Nas amostras mais deformadas o anfibólio ocorre em prismas alongados de até $0,2 \mathrm{~mm}$, orientados, isolados ou em agregados e intercrescidos com ilmenita e/ou leucoxênio. Seu pleocroísmo é verde claro a amarelo e verde azulado e o ângulo de extinção médio é de $12^{\circ}$, sugestivo de Fe-actinolita ou Fe-tschermakita. As distintas propriedades ópticas do anfibólio das duas variedades de amostras indi- cam que nas mais deformadas o mineral foi reestabilizado sob condições de pressão e temperatura mais baixas.

O plagioclásio das amostras menos deformadas também ocorre em duas variedades texturais. A mais abundante consiste de subgrãos milimétricos irregulares da matriz protomilonítica e outra, rara, em fenoclastos de 0,2 a $0,5 \mathrm{~mm}$ parcialmente saussuritizados. Na primeira os cristais são límpidos, não estão geminados e seu índice de refração é inferior ao do quartzo, sugestivo de albita. Os fenoclastos são geminados segundo a Lei Albita, o ângulo de extinção dos indivíduos é da ordem de $20^{\circ}$ e o índice de refração maior do que o do quartzo, indicativo de oligoclásio. A parcial saussuritização sugere que os fenoclastos poderiam ter sido, originalmente, labradorita.

O quartzo é anédrico não recuperado, de contornos irregulares e, nas amostras menos deformadas, além de participar da matriz cominuída, ocorre como inclusões poiquilíticas em anfibólio. $\mathrm{Na}$ matriz protomilonítica destas amostras e nas mais deformadas, o mineral ocorre em grãos milimétricos isolados ou em agregados lenticulares de subgrãos parcialmente recuperados.

Ilmenita é o mineral mais abundante (2 - 3\%) dentre os constituintes menores e ocorre em diminutos cristais tabulares, ora inclusos em anfibólio e ora alongados e intersticiais na matriz protomilonítica. A pirita é subédrica ou globular, de até $0,3 \mathrm{~mm}$, e ocorre apenas na matriz cominuída, o que sugere que o mineral se relaciona com a deformação. Zircão e apatita ocorrem em cristais submilimétricos euédricos, inclusos em anfibólio, intersticiais ou na matriz cominuída. Clorita é rara e está presente apenas na matriz cominuída, em particular em sombras de pressão das amostras mais deformadas.

A origem da uralitização destas amostras é ainda incerta, pois o processo pode ter ocorrido tanto durante os estágios finais da cristalização dos diques devido a uma parcial incorporação de fluidos das rochas encaixantes, quanto por influência da variável deformação posterior na presença de fluidos.

\section{Amostras com alteração avançada}

Diques de largura inferior a $5 \mathrm{~m}$ e bordas dos mais espessos contêm variadas proporções de minerais de alteração $\mathrm{e}$, nos menos espessos, os constituintes originais podem ou não estar presentes como fases reliquiares. As amostras com alteração compreendem dois grupos (Grupos 1 e 2) com distintas características mesoscópicas e composição mineral. Os intervalos de sondagem de ambos os grupos possuem fraturas rúpteis e venulações de carbonato.

Amostras do Grupo 1 - As amostras deste grupo são cinza escuro esverdeadas, muito finas, têm aspecto maciço ou possuem foliação incipiente a proeminente, indicativo 
de distintas intensidades de deformação durante ou após a alteração. A textura é lepidoblástica a granoblástica e porfiroclástica local dada por eventual anfibólio. Os minerais de alteração compreendem proporções variadas de biotita, clorita, quartzo e carbonato (Figura 5D).

A biotita é marrom e ocorre em três variedades texturais, presentes em distintas proporções entre as amostras. Uma substitui fenoclastos de anfibólio, outra é componente orientada da matriz cominuída e a última consiste de fenoclastos irregulares, de até $1 \mathrm{~mm}$, amendoados e com locais sombras de pressão. Nos três casos a biotita é residual por alteração para clorita.

A clorita ocorre como trama muito fina e suas propriedades ópticas variam entre as amostras. Em algumas tem pleocroísmo verde claro a branco e cor de interferência cinza, típica de Mg-clorita, ao passo que em outras é verde a branco e com cor de interferência azul, característica de Fe-clorita.

$\mathrm{O}$ quartzo ocorre em grãos milimétricos irregulares, não raro ameboides e intersticiais, ou em agregados granoblásticos intercrescidos com clorita e/ou biotita. Carbonato, além de constituinte de venulações, é errático, milimétrico e intersticial, ou ocorre como fenoclastos de até $0,2 \mathrm{~mm}$ límpidos e com discretas sombras de pressão, ou como fenoblastos de até $3 \mathrm{~mm}$ e com inclusões de quartzo e ilmenita (Figura 5E) e desenvolvidos sobre a foliação, indicativo de caráter tardio.

Amostras do Grupo 2 - As amostras deste grupo são cinza claro, finas a muito finas, foliadas e com disseminação irregular de cristais brancos milimétricos de carbonato. A textura é lepidoblástica fina, localmente porfiroblástica e seu constituinte maior é Mg-clorita (Figura 5E), com eventual quartzo, mica branca, carbonato e leucoxênio.

A sucessiva formação de biotita a partir de anfibólio, de clorita a partir de biotita e de mica branca a partir de clorita e biotita indicam hidrólise de intensidade variada entre as amostras, em resposta a distintas interações entre os diques e fluidos provenientes das rochas encaixantes, a mais extrema representada pelas amostras do Grupo 2. As evidências texturais sugerem que esta ocorreu durante a intrusão e resfriamento, com retomada na deformação posterior. A alteração ocorreu em pelo menos três estágios, o inicial representado pela transformação de anfibólio em biotita por incorporação de potássio, seguido da cloritização da biotita, sericitização da clorita e, talvez, concomitante alteração de ilmenita em leucoxênio, e o último marcado por carbonatação.

\section{GEOQUÍMICA}

De 21 amostras de núcleos, apenas 11 foram empregadas para análises químicas de rocha total por serem interpretadas como as mais próximas da composição mineral original e correspondem às amostras uralitizadas. Amostras das bor- das seriam mais adequadas para as determinações de composição química elementar, uma vez que deveriam corresponder a composições do líquido original e não a possíveis fracionados. Contudo, como as bordas dos diques contêm evidentes graus de transformação pós-magmática por interação com as rochas encaixantes, tornou-se mais adequado analisar as amostras distais em relação às bordas. As análises foram realizadas nos laboratórios da ACME Analytical Laboratories Ltd., Canadá. Os óxidos de elementos maiores e alguns elementos menores foram analisados por ICP-MS após fusão de $0,1 \mathrm{~g}$ de amostra em metaborato/tetraborato de Lítio e digestão em ácido nítrico diluído. Perda ao Fogo (P.F.) foi determinada por diferença de peso após aquecimento a $1.000^{\circ} \mathrm{C}$. ETR e elementos refratários foram analisados por ICP-MS a partir de $0,1 \mathrm{~g}$ de amostra submetida à mesma abertura que a empregada para determinar os óxidos de elementos maiores. Metais nobres e base foram determinados por ICP-MS após digestão de $0,5 \mathrm{~g}$ de amostra em Água Régia. Os resultados analíticos constam da Tabela 1 , com as amostras organizadas em ordem crescente de $\mathrm{SiO}_{2}$ e as proporções dos óxidos de elementos maiores representadas em base seca. Os erros analíticos são inferiores a $2 \%$.

A Perda ao Fogo é relativamente alta e varia de 2,3\% a $8,9 \%$ (média de $5,85 \% \pm 2,1 \%$ ), o que atesta graus variados de interação dos diques com fluidos provenientes das rochas encaixantes, em particular filitos carbonosos. As proporções de $\mathrm{SiO}_{2}$ variam de $43,63 \%$ a $48,17 \%, \mathrm{MgO}$ de $5,46 \%$ a $9,41 \%, \mathrm{CaO}$ de $3,7 \%$ a $9,2 \%, \mathrm{Fe}_{2} \mathrm{O}_{3}$ de $13,85 \%$ a $19,01 \%$ e álcalis $\left(\mathrm{Na}_{2} \mathrm{O}+\mathrm{K}_{2} \mathrm{O}\right)$ de $1,80 \%$ a $4,86 \%$, o que sugere diferenciação entre diques, mas compatível com a composição de basalto toleí́tico de alto ferro (Figura 6A). $\mathrm{O} \# \mathrm{mg}\left(\left[\mathrm{MgO} /\left(\mathrm{MgO}+\mathrm{Fe}_{2} \mathrm{O}_{3}\right)\right]\right.$ é baixo e varia entre $0,23 \mathrm{e}$ 0,37 e o teor de Ni entre 47 e $61 \mathrm{ppm}$. Magmas toleíticos derivados de manto possuem \#mg superior a $0,68 \mathrm{e}$ teor de $\mathrm{Ni}$ entre 300 e $500 \mathrm{ppm}$, o que sugere que os diques estudados representam magmas máficos diferenciados.

A composição do magma genitor não foi estimada em virtude de provável fracionamento dos núcleos dos diques, de onde provieram as amostras, somado às possíveis transformações pós-magmáticas e a ausência de determinações isotópicas que permitissem avaliar o grau de contaminação crustal. Mesmo assim, os dados geoquímicos indicam que os diques resultaram de fracionamento de plagioclásio e olivina (Figura 6B). Diagramas de Harker de óxidos de elementos maiores $v s$. \#mg oferecem pouca correlação o que é atribuído ao restrito intervalo composicional das amostras. Os diagramas também registram uma lacuna composicional entre dois grupos de amostras, sem significado petrológico e atribuída ao reduzido número de exemplares analisados e a ausência de amostras de composição intermediária.

Os elementos litófilos de grande raio (LIL) tais como $\mathrm{Ba}, \mathrm{Rb}, \mathrm{K}, \mathrm{Sr}$ e Th são em geral interpretados como mó- 
Tabela 1. Resultados analíticos de amostras de diques máficos que intrudem rochas metassedimentares do greenstone belt de Crixás. Óxidos de elementos maiores em \% em peso, recalculados para base seca. Elementos traço em ppm. Erros analíticos inferiores a $2 \%$.

\begin{tabular}{|c|c|c|c|c|c|c|c|c|c|c|c|}
\hline Amostra & 403 & 397 & 399 & 401 & 402 & 400 & 386 & 390 & 378 & 380 & 376 \\
\hline $\mathrm{SiO}_{2}$ & 43,63 & 43,75 & 43,94 & 43,97 & 44,03 & 44,61 & 44,99 & 46,47 & 46,77 & 48,13 & 48,17 \\
\hline $\mathrm{TiO}_{2}$ & 4,51 & 4,41 & 4,54 & 4,42 & 4,40 & 4,56 & 3,12 & 3,22 & 3,40 & 3,53 & 3,48 \\
\hline $\mathrm{Al}_{2} \mathrm{O}_{3}$ & 14,91 & 14,64 & 14,75 & 14,76 & 14,65 & 15,30 & 14,42 & 15,11 & 16,21 & 16,54 & 16,37 \\
\hline $\mathrm{Fe}_{2} \mathrm{O}_{3}$ & 18,03 & 17,66 & 18,11 & 18,18 & 17,61 & 18,84 & 19,01 & 18,21 & 13,95 & 15,92 & 15,39 \\
\hline $\mathrm{MgO}$ & 5,74 & 5,46 & 5,51 & 5,76 & 5,60 & 8,51 & 6,24 & 6,41 & 7,08 & 7,36 & 9,41 \\
\hline $\mathrm{CaO}$ & 7,83 & 8,31 & 8,56 & 9,20 & 7,37 & 5,40 & 8,44 & 7,52 & 8,58 & 3,70 & 3,90 \\
\hline $\mathrm{MnO}$ & 0,21 & 0,19 & 0,20 & 0,25 & 0,21 & 0,15 & 0,22 & 0,20 & 0,14 & 0,13 & 0,17 \\
\hline $\mathrm{Na}_{2} \mathrm{O}$ & 2,33 & 2,71 & 2,64 & 2,04 & 3,17 & 1,27 & 2,64 & 2,00 & 0,15 & 2,30 & 0,26 \\
\hline $\mathrm{K}_{2} \mathrm{O}$ & 1,63 & 1,70 & 0,56 & 0,27 & 1,81 & 0,17 & 0,27 & 0,17 & 3,00 & 1,56 & 2,10 \\
\hline $\mathrm{P}_{2} \mathrm{O}_{5}$ & 1,18 & 1,17 & 1,19 & 1,15 & 1,15 & 1,19 & 0,65 & 0,69 & 0,72 & 0,83 & 0,75 \\
\hline TOTAL & 100,00 & 100,00 & 100,00 & 100,00 & 100,00 & 100,00 & 100,00 & 100,00 & 100,00 & 100,00 & 100,00 \\
\hline P.F. & 5,1 & 6,5 & 7,0 & 7,1 & 2,5 & 6,4 & 2,3 & 7,0 & 8,9 & 4,4 & 7,2 \\
\hline \#mg & 0,24 & 0,23 & 0,23 & 0,24 & 0,24 & 0,31 & 0,24 & 0,26 & 0,33 & 0,31 & 0,37 \\
\hline $\mathrm{Cr}$ & 130 & 100 & 110 & 90 & 120 & 110 & 140 & 150 & 110 & 130 & 130 \\
\hline $\mathrm{Ni}$ & 48 & 52 & 53 & 52 & 55 & 47 & 61 & 65 & 58 & 56 & 61 \\
\hline Co & 46 & 46 & 44 & 44 & 45 & 49 & 47 & 46 & 43 & 46 & 37 \\
\hline $\mathrm{V}$ & 133 & 125 & 118 & 115 & 129 & 128 & 157 & 149 & 157 & 168 & 176 \\
\hline Sc & 21 & 20 & 21 & 20 & 21 & 21 & 26 & 26 & 27 & 28 & 30 \\
\hline $\mathrm{TI}$ & 0,7 & 1,4 & 0,4 & 0,1 & 1,4 & $<0,1$ & 0,1 & 0,1 & 0,4 & 0,8 & 0,2 \\
\hline $\mathrm{Rb}$ & 59 & 93 & 22 & 11 & 90 & 6 & 5 & 8 & 48 & 49 & 37 \\
\hline $\mathrm{Sr}$ & 194 & 201 & 224 & 283 & 143 & 164 & 206 & 163 & 103 & 214 & 62 \\
\hline Mo & 2,1 & 2,2 & 2,3 & 2,1 & 2,7 & 2,2 & 2,3 & 1,5 & 2,2 & 3,1 & 2,1 \\
\hline $\mathrm{Cu}$ & 28 & 44 & 60 & 30 & 34 & 32 & 39 & 70 & 61 & 1,1 & 29 \\
\hline $\mathrm{Pb}$ & 3 & 7 & 8 & 5 & 6 & 9 & 2 & 3 & 5 & 2 & 2 \\
\hline $\mathrm{Zn}$ & 150 & 166 & 261 & 240 & 173 & 494 & 117 & 164 & 151 & 149 & 233 \\
\hline $\mathrm{Ba}$ & 540 & 484 & 298 & 70 & 385 & 106 & 38 & 15 & 750 & 670 & 834 \\
\hline $\mathrm{Nb}$ & 31,2 & 30,3 & 30,2 & 29,3 & 31,5 & 31,0 & 17,2 & 15,8 & 17,0 & 19,7 & 18,5 \\
\hline $\mathrm{Ta}$ & 1,7 & 1,7 & 1,8 & 1,7 & 1,9 & 1,8 & 1,0 & 0,9 & 1,0 & 1,1 & 1,1 \\
\hline W & 0,7 & 0,5 & 0,7 & 0,4 & 0,4 & 0,4 & 0,3 & 0,5 & 3,5 & 0,9 & 0,9 \\
\hline Th & 3,6 & 2,9 & 3,8 & 2,7 & 3,5 & 2,9 & 2,2 & 1,9 & 2,0 & 2,3 & 3,1 \\
\hline$U$ & 0,9 & 0,8 & 0,9 & 0,8 & 0,9 & 1,1 & 0,5 & 0,5 & 0,6 & 0,5 & 1,2 \\
\hline Cs & 6,4 & 10,7 & 3,3 & 1,1 & 13,8 & 0,2 & 0,3 & 0,5 & 2,6 & 5,0 & 1,7 \\
\hline $\mathrm{Ga}$ & 22,1 & 21,7 & 20,5 & 19,5 & 22,1 & 22,5 & 19,4 & 18,8 & 20,0 & 21,2 & 21,0 \\
\hline $\mathrm{Hf}$ & 6,8 & 6,9 & 6,8 & 6,8 & 6,9 & 7,2 & 4,7 & 4,5 & 5,0 & 5,7 & 5,3 \\
\hline $\mathrm{Zr}$ & 302 & 293 & 291 & 287 & 301 & 309 & 192 & 185 & 200 & 222 & 210 \\
\hline$Y$ & 46 & 45 & 44 & 43 & 46 & 43 & 35 & 32 & 32 & 39 & 50 \\
\hline $\mathrm{La}$ & 36,4 & 37,7 & 37,0 & 34,3 & 37,8 & 37,5 & 21,7 & 20,7 & 24,3 & 25,4 & 28,7 \\
\hline $\mathrm{Ce}$ & 81,2 & 81,3 & 81,9 & 77,0 & 82,6 & 81,3 & 49,5 & 47,7 & 51,8 & 56,8 & 64,7 \\
\hline $\mathrm{Pr}$ & 11,31 & 11,06 & 11,01 & 10,40 & 11,37 & 11,10 & 6,86 & 6,56 & 7,05 & 7,78 & 9,00 \\
\hline $\mathrm{Nd}$ & 48,0 & 48,2 & 48,1 & 45,1 & 51,0 & 48,9 & 30,4 & 30,1 & 31,4 & 34,1 & 40,8 \\
\hline $\mathrm{Sm}$ & 10,42 & 9,86 & 9,92 & 9,34 & 10,10 & 9,83 & 6,97 & 6,33 & 7,09 & 7,66 & 9,03 \\
\hline $\mathrm{Eu}$ & 2,81 & 2,75 & 2,88 & 2,62 & 2,85 & 3,02 & 2,11 & 2,02 & 2,14 & 2,41 & 2,53 \\
\hline $\mathrm{Gd}$ & 9,54 & 9,24 & 8,79 & 8,76 & 9,22 & 9,01 & 6,36 & 6,16 & 7,01 & 7,53 & 9,08 \\
\hline $\mathrm{Tb}$ & 1,59 & 1,54 & 1,51 & 1,44 & 1,59 & 1,51 & 1,11 & 1,08 & 1,14 & 1,35 & 1,56 \\
\hline Dy & 8,61 & 8,26 & 8,36 & 7,88 & 8,37 & 8,02 & 6,30 & 6,00 & 5,92 & 7,49 & 8,68 \\
\hline $\mathrm{Ho}$ & 1,56 & 1,51 & 1,55 & 1,46 & 1,61 & 1,45 & 1,18 & 1,10 & 1,13 & 1,38 & 1,67 \\
\hline $\mathrm{Er}$ & 4,33 & 4,21 & 4,26 & 4,10 & 4,25 & 4,09 & 3,29 & 2,92 & 3,09 & 3,67 & 4,65 \\
\hline $\mathrm{Tm}$ & 0,61 & 0,64 & 0,58 & 0,59 & 0,60 & 0,61 & 0,48 & 0,44 & 0,49 & 0,53 & 0,70 \\
\hline $\mathrm{Yb}$ & 3,55 & 3,48 & 3,37 & 3,32 & 3,60 & 3,35 & 2,74 & 2,37 & 2,75 & 2,73 & 3,92 \\
\hline $\mathrm{Lu}$ & 0,57 & 0,56 & 0,56 & 0,56 & 0,59 & 0,58 & 0,44 & 0,39 & 0,45 & 0,43 & 0,61 \\
\hline ETR & 16,14 & 15,82 & 15,32 & 15,09 & 16,36 & 15,23 & 12,45 & 10,77 & 12,50 & 12,41 & 17,82 \\
\hline $\mathrm{LaN} / \mathrm{YbN}$ & 6,84 & 7,22 & 7,32 & 6,89 & 7,00 & 7,46 & 5,28 & 5,82 & 5,89 & 6,20 & 4,88 \\
\hline
\end{tabular}



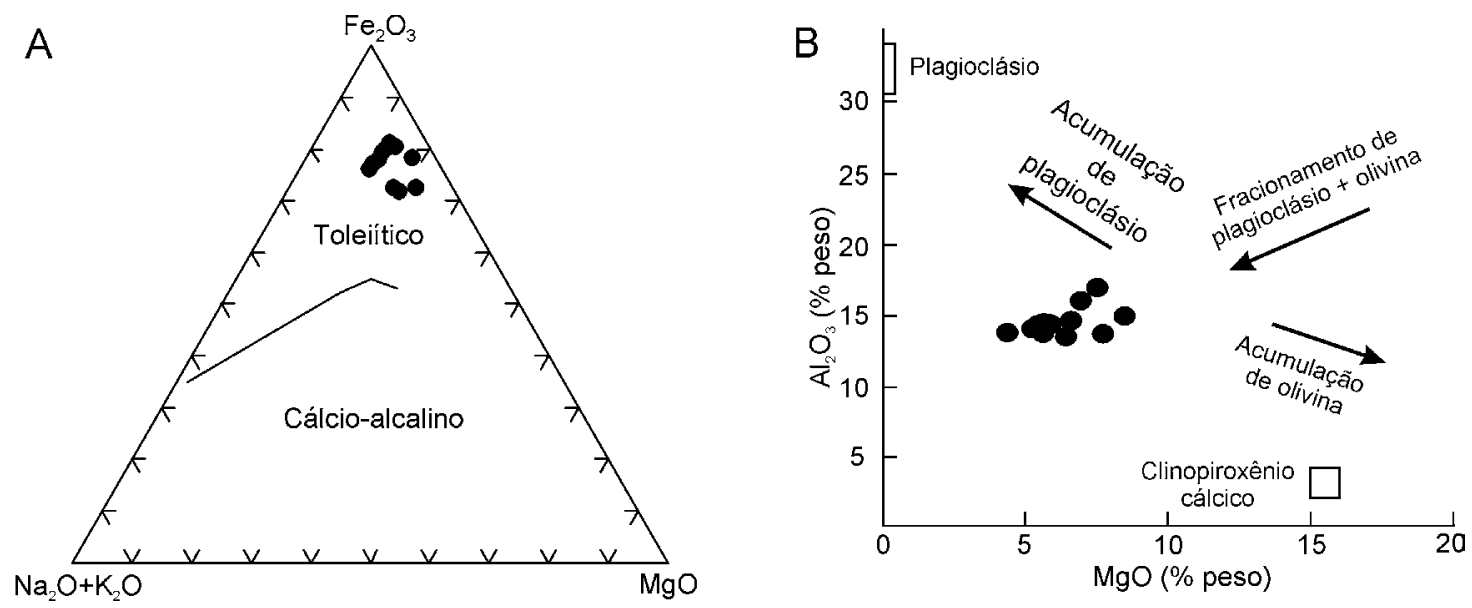

Figura 6. A. Diagrama AFM que mostra o caráter toleíitico de alto ferro dos diques estudados. Campos segundo Irvine e Baragar (1971). B. Diagrama $\mathrm{Al}_{2} \mathrm{O}_{3} \times \mathrm{MgO}$ que revela que os diques resultaram de fracionamento de plagioclásio e olivina (modificado de Wilson, 1989, p. 136).

veis durante a alteração e metamorfismo de baixo grau (Pearce, 1982). Entretanto, elementos incompatíveis (Nb, Ti, Zr, P, Hf, Ta, Y, Ni, Cr) e HREE que são relativamente imóveis durante a alteração e metamorfismo de baixo grau podem ser empregados para reconhecer aspectos petrológicos e de ambiente tectônico. Para superar a baixa correlação entre óxidos de elementos maiores com o \#mg, atribuída à uralitização dos núcleos, empregou-se a variação de $\mathrm{TiO}_{2}, \mathrm{P}_{2} \mathrm{O}_{5}, \mathrm{Y}, \mathrm{Cr}, \mathrm{V}$ e Y com Zr (Figura 7), o que resul- tou em correlação positiva de $\mathrm{TiO}_{2}, \mathrm{P}_{2} \mathrm{O}_{5}$ e $\mathrm{Y}$ e negativa de $\mathrm{Cr}, \mathrm{V}$ e $\mathrm{Ni}$ com $\mathrm{Zr}$, indicativos de tendências normais de diferenciação magmática.

O $\Sigma$ ETR das 11 amostras varia de 10,77 a 17,82 ppm, seus padrões normalizados ao condrito de Nakamura (1977) são fracionados (Figura $8 \mathrm{~A}$ ), com valores de $\mathrm{La}_{\mathrm{N}} / \mathrm{Yb}_{\mathrm{N}}$ entre 4,88 e 7,46, e anomalia de Eu ausente ou extremamente reduzida, tanto positiva quanto negativa. $\mathrm{O}$ padrão destas amostras é semelhante ao de basaltos continentais, como
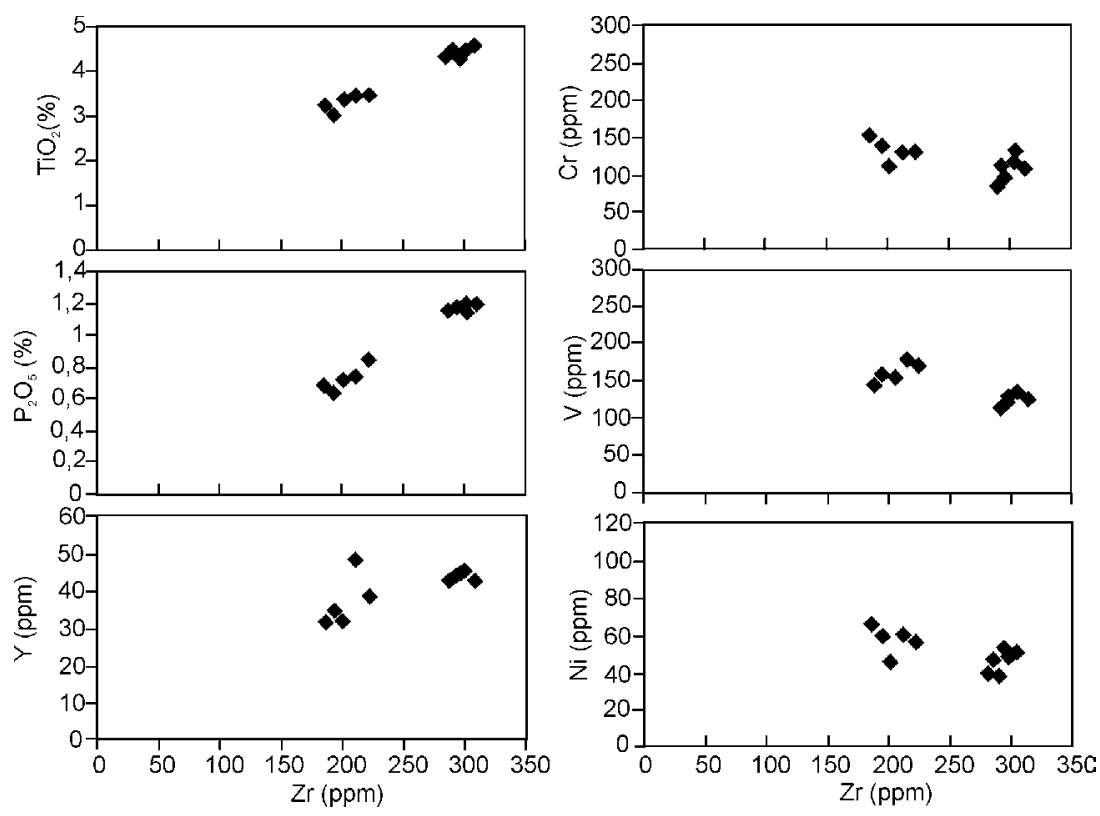

Figura 7. Diagramas de variação de $\mathrm{TiO}_{2}, \mathrm{P}_{2} \mathrm{O}_{5}, \mathrm{Y}, \mathrm{Cr}, \mathrm{V}$ e Ni com $\mathrm{Zr}$ das amostras de diques de Crixás que mostram que os mesmos resultaram de diferenciação magmática. 
descrito por Wilson (1989), e aos diques de 2,3 a 2,4 Ga intrusivos nos complexos granito-gnáissicos arqueanos do SW do greenstone belt de Crixás, estudados por Kuyumjian (1998) e Corrêa da Costa (2003) (Figura 8B).

O diagrama multielementar normalizado ao manto primitivo (Figura $8 \mathrm{C}$ ) evidencia que as amostras comportam dois grupos. $\mathrm{O}$ dominante é mais enriquecido em $\mathrm{Rb}_{\mathrm{N}}, \mathrm{Ba}_{\mathrm{N}}$ e $\mathrm{K}_{\mathrm{N}}$ e possui reduzida anomalia negativa de $\mathrm{Nb}_{\mathrm{N}}$ e contrasta com três amostras empobrecidas em $\mathrm{Rb}_{\mathrm{N}}, \mathrm{Ba}_{\mathrm{N}}$ e $\mathrm{K}_{\mathrm{N}}$ e com anomalia levemente positiva de $\mathrm{Nb}_{\mathrm{N}}$. Estas diferenças podem ser atribuídas tanto a distintos líquidos originais quanto ao fracionamento durante o resfriamento e mesmo a diferentes graus de contaminação crustal. Contudo, ambos os grupos possuem forte anomalia negativa de $\mathrm{Sr}_{\mathrm{N}}$ e positiva de $\mathrm{Ti}_{\mathrm{N}}$. Segundo Weaver e Tarney (1984), rochas máficas submetidas à contaminação crustal forneceriam diagramas multielementares normalizados ao man- to primitivo com anomalias negativas de $\mathrm{Nb}$ e $\mathrm{Ti}$. A presença de anomalias tanto positivas quanto negativas de $\mathrm{Nb}$ nas amostras sugere variável contaminação crustal, não registrada pela anomalia positiva de Ti. Contudo, estas observações guardam incertezas quanto às suas causas em virtude dos limitados dados disponíveis.

O diagrama multielementar normalizado ao manto primitivo de diques de alto-Ti de 2,3 - 2,4 Ga dos complexos granito-gnáissicos arqueanos adjacentes ao greenstone belt de Crixás (Figura 8D) (Corrêa da Costa, 2003), sobreposto pela média dos basaltos da Bacia do Paraná (Bellieni et al., 1986), N-MORB (Lê Roex et al., 1983) e P-MORB (Lê Roex et al., 1985) registra que o padrão das amostras analisadas é semelhante a ambos os casos.

Diagramas discriminantes de ambiente tectônicos com o emprego de elementos traços imóveis (Figura 9) registram que as amostras estudadas se situam nos campos dos ba-
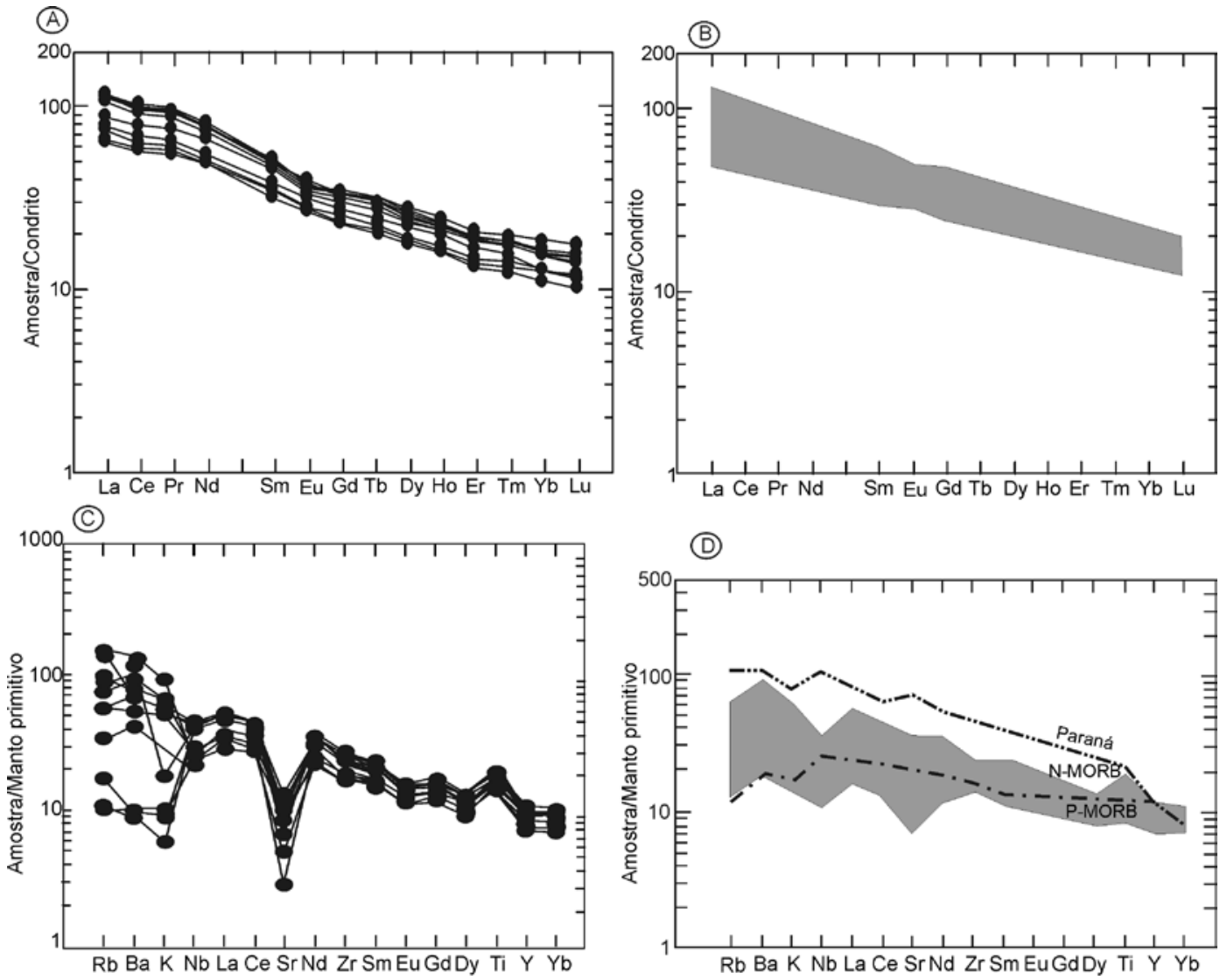

(D)

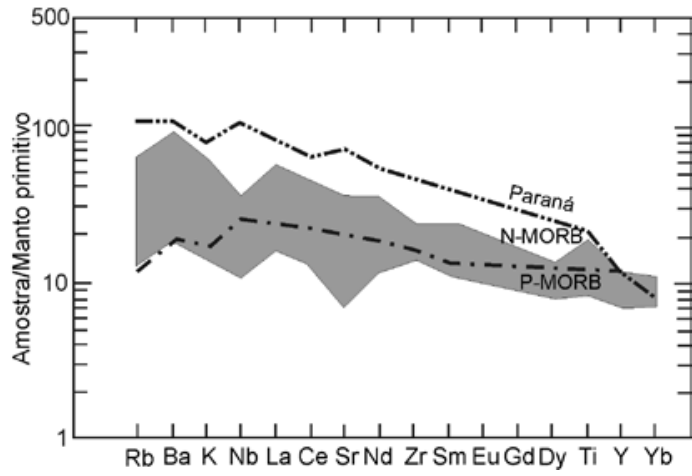

Figura 8. A. Padrões de ETR normalizados ao condrito (Nakamura, 1977) dos diques de Crixás. B. Padrões de ETR normalizados ao condrito (Boynton, 1984, recalculados segundo dados de Nakamura, 1977) de diques máficos intrusivos em complexos granito-gnáissicos arqueanos de Goiás (Kuyumiian, 1998; Corrêa da Costa, 2003). C. Diagrama multielementar normalizado ao manto primitivo (Sun e McDonough, 1989) das amostras de diques de Crixás. D. Diagrama multielementar normalizado ao manto primitivo das amostras de diques máficos intrusivos em complexos granito-gnáissicos arqueanos de Goiás (Corrêa da Costa, 2003). 


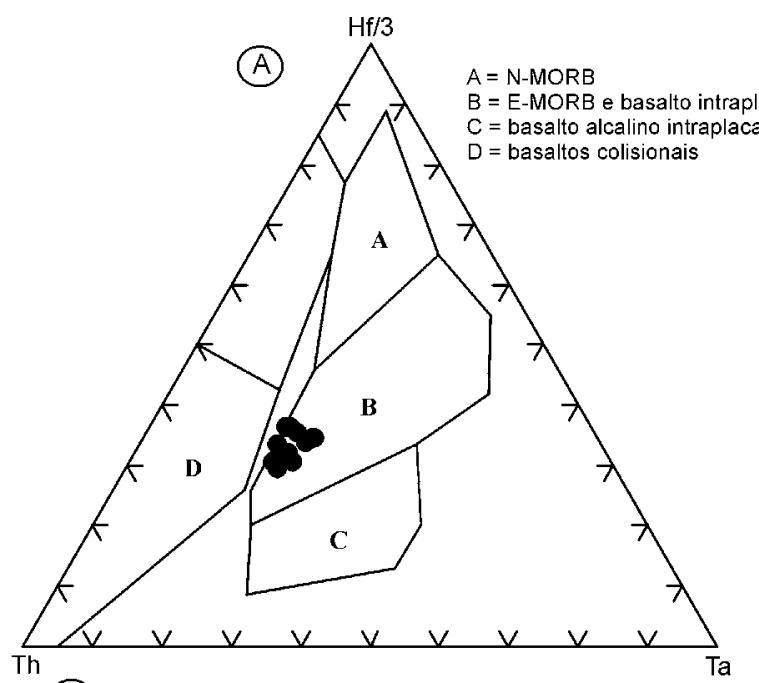

(C)

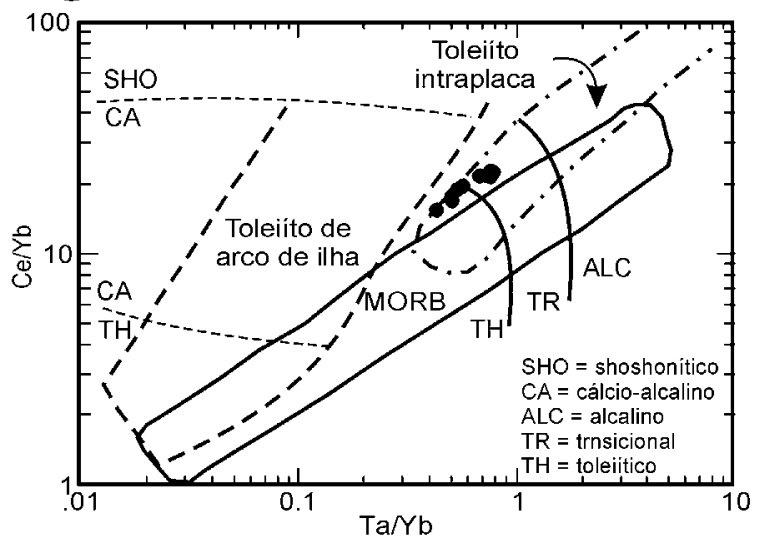

(E)

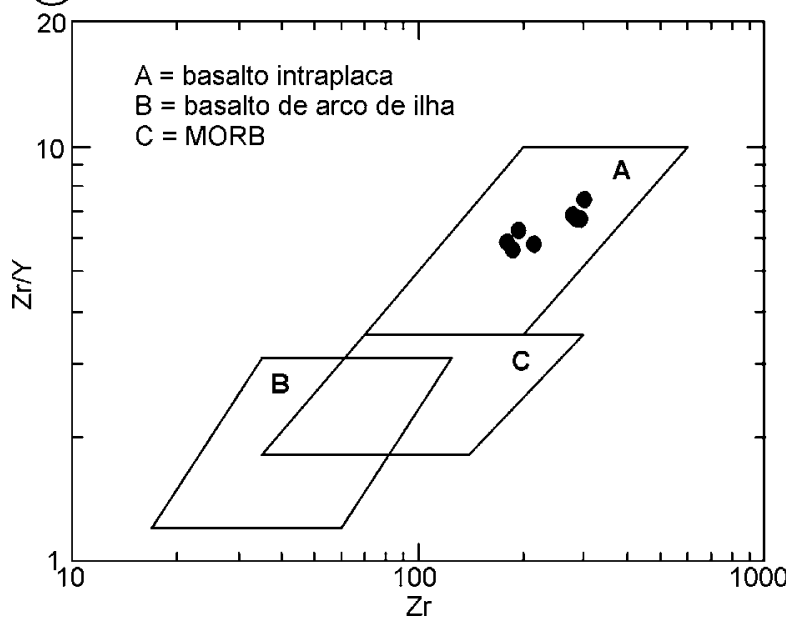

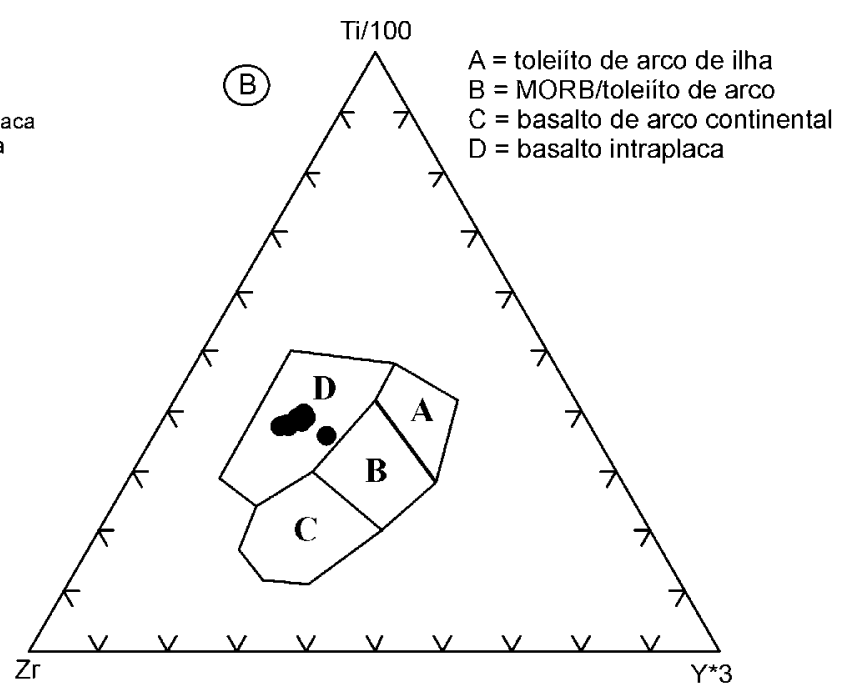

(D)

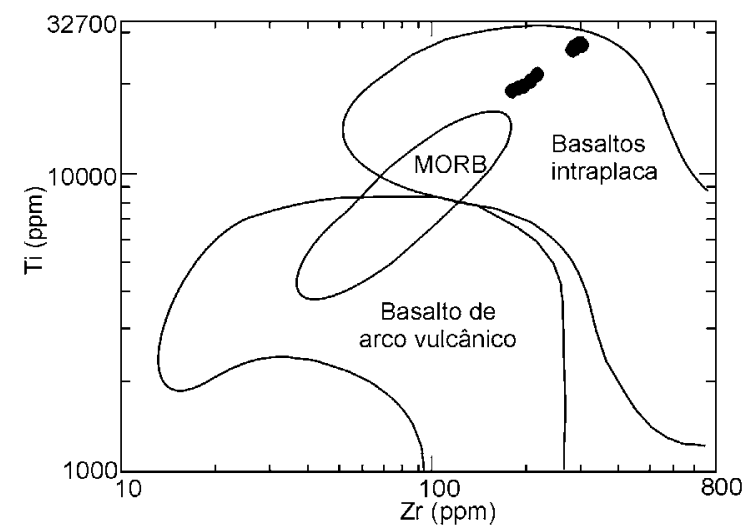

(F)

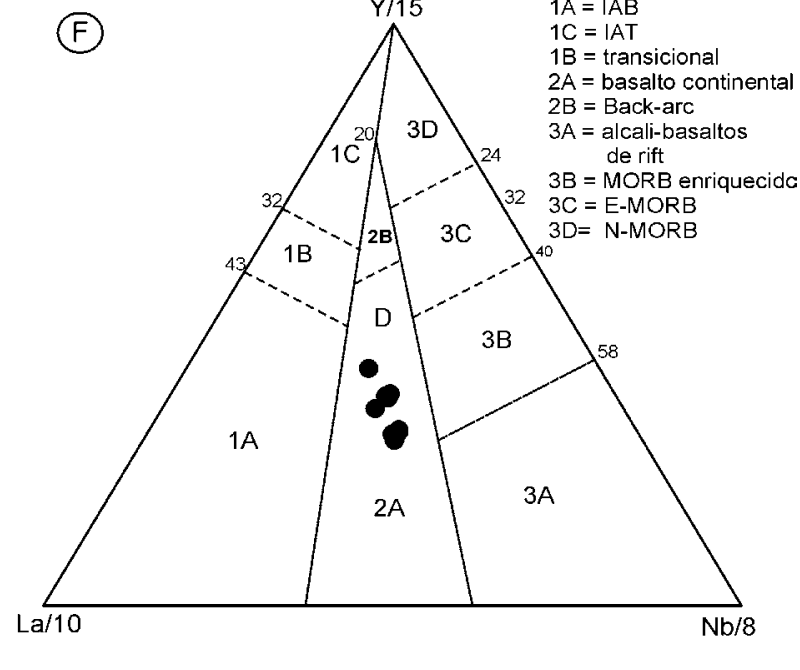

Figura 9. Distribuição dos dados analíticos de elementos traço das amostras dos diques de Crixás em diagramas discriminantes de ambientes tectônicos que mostra a sua compatibilidade com basaltos intraplaca, em particular com basaltos continentais (Figura 9F). Diagramas segundo (A) Wood (1980), (B) Pearce e Cann (1973), (C) Pearce (1982), (D) Pearce e Cann (1973), (E) Pearce e Norris (1979) e (F) Cabanis e Lécolle (1989). 
saltos intraplaca. A despeito da uralitização das amostras, a comparação das razões entre seus elementos traços com as de basaltos continentais reunidos por Wilson (1989) mostra que valor médio de $\mathrm{Zr} / \mathrm{Y}(5,95)$ dos diques estudados é intermediária entre a dos basaltos das províncias do Deccan e da Bacia do Paraná (4,1 e 9,4, respectivamente), a razão Ta/ $\mathrm{Yb}(0,43)$ é compatível com a dos basaltos da primeira $(0,4)$ e a $\mathrm{Zr} / \mathrm{Nb}(10,35)$ com os da última $(10,7)$.

\section{CONCLUSÕES}

Do exposto se conclui que os diques máficos estudados, de idade 2,17 Ga (Jost et al., 2010), retratam a ocorrência de evento magmático que atingiu a seção metassedimentar do greenstone belt de Crixás até então desconhecido no contexto dos terrenos arqueanos de Goiás. A natureza geoquímica dos diques mostra que estes são de alto-Ti e compatível com magmatismo epicratônico semelhante aos basaltos da Bacia do Paraná. É provável que a ocorrência de diques sincrônicos possa ser registrada em meio às seções de rochas metavulcânicas inferiores de 3,0 Ga bem como no interior dos gnaisses arqueanos adjacentes e, assim, que nem todos os diques máficos que ocorrem em meio aos metakomatiitos e metabasaltos sejam co-produtos do vulcanismo datado em 3,0 Ga por Fortes et al. (2003).

A idade dos diques corresponde ao Rhyaciano (2300 a $2050 \mathrm{Ma}$ ), período durante o qual o Globo Terrestre foi palco de intensa atividade magmática máfica, com vulcanismo e, não raro, plutonismo de grande porte como o Complexo de Bushveld. Condie (2001) atribui os processos desta natureza a eventos de superplumas mantélicas e fragmentação de continentes e que, no Pré-cambriano, ocorreram em 2,75 - 2,70 Ga, 2,45 e 2,0 - 1,9 Ga, com vários possíveis eventos menores entre 2,5 e 1,75 Ga. Segundo o autor, o pico de $2,45 \mathrm{Ga}$ corresponde ao de formação de crosta juvenil registrado nos crátons da Índia e China e o de 2,1 - 2,15 Ga à formação de crosta no Escudo das Guinas e África Oriental. Por outro lado, Halls e Davies (2004) registram a ocorrência de enxame de diques máficos de 2,17 Ga no norte do Canadá, onde Ernst e Buchan (2004) descrevem que o intervalo de 2,19 a 2,17 Ga foi período de intensa atividade magmática básica e formação de vários enxames de diques. Aparentemente, a atividade magmática deste curto intervalo de tempo não teve a expressão global de outros eventos do Pré-cambriano relacionados com superplumas. Os dados aqui obtidos indicam que os diques estudados pertencem a este evento e representam um novo episódio de extensão crustal na região arqueana de Goiás. Este evento é posterior em cerca de $130 \mathrm{Ma}$ aos diques e stocks que ocorrem nos complexos granito-gnáissicos arqueanos adjacentes e correlacionáveis ao pico de plumas mantélicas de $2,45 \mathrm{Ga}$, o que introduz novos elementos ao quadro evolutivo do terreno arqueano de Goiás mediante a constatação de uma segunda fase de eventos epicratônicos.

\section{AGRADECIMENTOS}

Ao Conselho Nacional de Desenvolvimento Científico e Tecnológico - CNPq pelo suporte financeiro para trabalhos de campo e análises químicas (Proc. 304764/2007-6), à Mineração Serra Grande S.A. pelo acesso aos testemunhos de sondagem e liberação das amostras. Ao Prof. Dr. Vicente Antonio Vitório Girardi e aos revisores anônimos pelas valiosas sugestões ao manuscrito.

\section{REFERÊNCIAS}

BELLIENI, G.; COMIN-CHIARAMONTI, P.; MARQUES, L. S.; MELFI, A. J.; NARDY, A. J. R.; PAPATRECHAS, C.; PICCIRILLO, E. M.; ROISEMBERG, A.; STOLFA, D. Petrogenetic aspects of acid and basaltic lavas from the Paraná Plateau (Brazil): geological, mineralogical and petrological relationships. Journal of Petrology, v. 27, p. 915-944, 1986.

BOYNTON, W. V. Cosmochemistry of rare earth elements: meteorite studies. In: HENDERSON, P. (Ed.) Rare Earth Element Geochemistry. Amsterdam/ New York: Elsevier, 1984. p. 63-114.

CABANIS, B.; LECOLLE, M. Le diagramme La/10-Y/15$\mathrm{Nb} / 8$ : un outil pour la discrimination des séries volcaniques et la mise en evidence des processus de mélange et/ou de contamination crustales. Comptes Rendus de l'Académie des Sciences de Paris, Série 2, v. 309, p. 2023-2029, 1989.

CONDIE, K. Mantle Plumes and their record in Earth History. Cambrigde: Cambridge University Press, 2001. 336 p.

CORRÊA DA COSTA, P. C.; GIRARDI, V. A. V. Geochemistry and Sr-Nd isotopes of the Paleoproterozoic mafic dykes from the Goiás-Crixás Archean block, Goiás State, Brazil. Revista Brasileira de Geociências, v. 35, p. 135-150. 2005.

CORRÊA DA COSTA, P. C. Petrologia, geoquímica e geocronologia dos diques máficos da região de CrixásGoiás, porção centro-oeste do Estado de Goiás. 2003. 151 f. Tese (Doutorado) - Instituto de Geociências, Universidade de São Paulo, São Paulo, 2003.

CORRÊA DA COSTA, P. C.; GIRARDI, V. A. V.; TEIXEIRA, W. Petrologia dos diques máficos da região de Crixás-Goiás, porção centro-oeste do Estado de Goiás. In: 
CONGRESSO BRASILEIRO DE GEOLOGIA, 41, 2002, João Pessoa. Anais... João Pessoa: SBG, 2002. p. 418.

CORRÊA DA COSTA, P. C.; GIRARDI, V. A. V.; TEIXEIRA, W. 40Ar/39Ar and Rb/Sr geochronology of the Goiás-Crixás dike swarm, Central Brazil: constraints of the Neoarchean-Paleoproterozoic tectonic boundary in South America and Nd-Sr signature of the subcontinental mantle. International Geology Review, v. 48, p. 547-560, 2006.

ERNST, L. E.; BUCHAN, K. L. Igneous rock associations in Canada 3. Large Igneous Provinces (LIPs) in Canada and adjacent regions: 3 Ga to Present. Geoscience Canada, v. 31, p. 103-126, 2004.

FORTES, P. T. F. O.; PIMENTEL, M. M.; TEIXEIRA, $\mathrm{W}$. Geocronologia $\mathrm{Rb}-\mathrm{Sr}$ das rochas encaixantes do depósito aurífero Mina III, Goiás. In: CONGRESSO BRASILEIRO DE GEOQUÍMICA, 4., 1993, Niterói. Resumos Expandidos... Niterói: SBGq, 1993. p. 250-252.

FORTES, P. T. F. O.; CHEILLETZ, A.; GIULIANI, G.; FÉRAUD, G. A. Brasiliano age ( $500 \pm 5 \mathrm{Ma})$ for the Mina III gold deposit, Crixás Greenstone Belt, Central Brazil. International Geology Review, v. 39, p. 449-460, 1997.

FORTES, P. T. F. O.; PIMENTEL, M. M.; SANTOS, R. V.; JUNGES, S. L. Sm-Nd studies at Mina III gold deposit, Crixás greenstone belt, Central Brazil: implications for the depositional age of the upper metasedimentary rocks and associated Au mineralization. Journal of South American Earth Sciences, v. 16, p. 503-512, 2003.

GIRARDI, V. A. V.; MAZZUCCHELLI, M.; MOLESINI, M.; FINATTI, M. C.; RIVALENTI, G.; CORREIA, C. T. Petrological and geochemical aspects of mafic dykes of Goiás State, Brazil. In: SBG, CONGRESSO BRASILEIRO DE GEOLOGIA, 37., 1992, São Paulo, Anais... São Paulo: SBG, 1992. v. 1, p. 490-495.

HALLS, H. C.; DAVIES, D. W. Paleomagnetism and $\mathrm{U}-\mathrm{Pb}$ geochronology of the $2.17 \mathrm{Ga}$ Biscotasing dyke swarm, Ontario, Canada: evidence for vertical-axis crustal rotation across the Kapuskasing Zone. Canadian Journal of Earth Sciences, v. 31, p. 255-269, 2004.

IRVINE, T. N.; BARAGAR, W. R. A. A guide to the chemical classification of common rocks. Canadian Journal of Earth Sciences, v. 8, p. 523-548, 1971.

JOST, H.; OLIVEIRA, A. M. Stratigraphy of the greenstone belts, Crixás region, Goiás, Central Brazil.
Journal of South American Erath Sciences, v. 4, p. 201-214, 1991.

JOST,H.;DUSSIN, I. A.; CHEMALEJR., F.; TASSINARI, C. C. G.; JUNGES, S. U-Pb and Sm-Nd constraints for the Paleoproterozoic age of the metasedimentary sequences of the Goiás Archean greenstone belts. In: SOUTH AMERICAN SYMPOSIUM ON ISOTOPE GEOLOGY, 6., 2008, San Carlos de Bariloche. Proceedings... San Carlos de Bariloche: INGEIS, 2008. 1 CD-ROM.

JOST, H.; CHEMALE JR., F.; DUSSIN, I. A.; TASSINARI, C. C. G.; MARTINS, R. A U-Pb zircon Paleoproterozoic age for the metasedimentary host rocks and gold mineralization of the Crixás greenstone belt, Goiás, Central Brazil. Ore Geology Reviews, v. 37, p. 127-139, 2010.

KUYUMJIAN, R. M. Mafic dike swarms of the Goiás Massif, Central Brazil. Revista Brasileira de Geociências, v. 28, p. 45-50, 1998.

LÊ ROEX, A. P.; DICK, H. J. B.; ERLANK, A. J.; REID, A. M.; FREY, F. A.; HART, S. R. Geochemistry, mineralogy and petrogenesis of lavas erupted along the Southwest Indian Ridge between the Bouvet triple junction and 11 degrees East. Journal of Petrology, v. 24, p. $267-318,1983$.

LÊ ROEX, A. P.; DICK, H. J. B.; REID, A. M.; FREY, F. A.; ERLANK, A. J.; HART, S. R. Petrology and geochemistry of basalts from the American-Antartic ridge, Southern Ocean: implications from the westward influence of the Bouvet mantle plume. Contributions to Mineralgy and Petrology, v. 90, p. 367-380, 1985.

MAGAlHÃES, L. F. Cinturão de cisalhamento de empurrão Córrego Geral-Meia Pataca: geologia, deformação, alteração hidrotermal e mineralizações auríferas associados, Crixás, Goiás. 1991. Dissertação (Mestrado) - Instituto de Geociências, Universidade de Brasília, Brasília, 1991.

MASSUCATO, A. J. Aspectos estruturais do greenstone belt de Crixás. Relatório de Geologia Estrutural. AngloGold Ashanti Mineração Ltda, 2004. (Relatório Interno).

NAKAMURA, N. Determination of REE, Ba, $\mathrm{Fe}, \mathrm{Mg}, \mathrm{Na}$ and $\mathrm{K}$ in carbonaceous and ordinary chondrites. Geochemica et Cosmochemica Acta, v. 38, p. $757-775,1977$. 
PEARCE, J. A. Trace element characteristics of lavas from descructive plate boundaries. In: THORPE, S. Andesites: orogenic andesites and related rocks. Chichester: Wiley, 1982. p. 525-548.

PEARCE, J. A.; CANN, J. R. Tectonic setting of basic volcanic rocks determining using trace element analysis. Earth Planetary Science Letters, v. 19, p. 290-300, 1973.

PEARCE, J. A.; NORRIS, M. J. Petrogenetic implications of $\mathrm{Ti}, \mathrm{Zr}, \mathrm{Y}$ and $\mathrm{Nb}$ variations in volcanic rocks. Contributions to Mineralogy and Petrology, v. 69, p. 33-47, 1979.

QUEIROZ, C. L. Caracterização dos domínios estruturais e da arquitetura do greenstone belt de Crixás, GO. 1995. 115 f. Dissertação (Mestrado) - Instituto de Geociências, Universidade de Brasília, Brasília, 1995.

QUEIROZ, C. L.; JOST, H.; SILVA, L. C.; MCNAUGHTON, N. J. U-Pb SHRIMP and Sm$\mathrm{Nd}$ geochronology of granite-gneiss complexes and implications for the evolution of the central Brazil Archean terrain. Journal of South American Earth Sciences, v. 26, p. 100-124, 2008.

SABÓIA, L. A. Os greenstone belts de Crixás e Goiás, Go. Sociedade Brasileira de Geologia Núcleo Centro-Oeste, Boletim Informativo, n. 9, p. 44-72, 1979.

SUN, S. S.; MCDONOUGH, W. F. Chemical and isotopic systematics of oceanic basalts: implications for mantle composition and processes. In: SAUNDERS, A. D.; NORRY, M. J. (Ed.). Magmatism in the ocean basins. Oxford: Blackwell1, 1989. p. 313-345. (Geological Society Special Publication, 42).

TASSINARI, C. C. G.; JOST, H.; SANTOS, J. C.; NUTMAN, A. P.; BENNELL, M. R. Pb and Nd isotope signatures and SHRIMP U-Pb geochronological evidence of Paleoproterozoic age for Mina III gold mineralization, Crixás District, Central Brazil. In: SOUTH AMERICAN SYMPOSIUM ON ISOTOPE GEOLOGY, 5., 2006, Punta del Este. Short Papers... Buenos Aires : Idea Gráfica, 2006. p. 527-529.

TOMAZZOLI, E. R.; NILSON, A. A. Diques máficoultramáficos de Goiás: aspectos petrológicos. In: CONGRESSO BRASILEIRO DE GEOLOGIA, 38., 1994, São Paulo. Anais... São Paulo: SBG, 1994. v. 1. p. 63-65.

TOMAZZOLI, E. R. Aspectos geológicos e petrológicos do enxame de diques Morro Agudo de Goiás. 1997. 285 f.
Tese (Doutorado) - Instituto de Geociências, Universidade de Brasília, Brasília, 1997.

WEAVER, B. L.; TARNEY, J. Empirical approach to estimating the composition of the continental crust. Nature, v. 310, p. 575-577, 1984.

WILSON, M. Igneous petrogenesis. London: Unwin Hyman, 1989. 465 p.

WOOD, D. A. The application of a Th-Hf-Ta diagram to problems of tectonomagmatic classification and to establishing the nature of crustal contamination of basaltic lavas of the British Tertiary volcanic province. Earth and Planetary Science Letters, v. 50, p. 11-30, 1980. 